\title{
Experimental Study on Equivalent Strength of Induced Joints with consideration to Influence of Concrete Strength, Inducer Spacing, and Concrete Age
}

\author{
Xiaofei Zhang $\mathbb{D}^{1},{ }^{1}$ Peipei Wei $\mathbb{D}^{1},{ }^{1}$ Xin Zhang, ${ }^{2}$ Tao Yan, ${ }^{1}$ Gangfeng Zheng, ${ }^{3}$ and \\ Wenwei Zhang ${ }^{1}$ \\ ${ }^{1}$ State Key Laboratory of Eco-hydraulics in Northwest Arid Region, Xi'an University of Technology, Xi'an 710048, China \\ ${ }^{2}$ Hanjiang-to-Weihe River Valley Water Diversion Project Construction Co. Ltd, Shaanxi Province, Xi'an 710100, China \\ ${ }^{3}$ Zhejiang Design Institute of Water Conservancy and Hydroelectric Power, Hangzhou 310000, China
}

Correspondence should be addressed to Xiaofei Zhang; zhangxiaofei_lgd@163.com

Received 17 December 2019; Revised 23 October 2020; Accepted 27 November 2020; Published 17 December 2020

Academic Editor: Roman Wan-Wendner

Copyright (C) 2020 Xiaofei Zhang et al. This is an open access article distributed under the Creative Commons Attribution License, which permits unrestricted use, distribution, and reproduction in any medium, provided the original work is properly cited.

\begin{abstract}
To prevent the occurrence of temperature cracking, the induced joints of dams are typically arranged to reduce the tensile strength and orderly guide the crack to form at an induced joint, which can protect the dam structure. The state of the joint surface and the equivalent strength and arrangement of the induced joints have important practical significance for preventing the disorderly cracking of the dam. In this study, the concrete strength, inducer spacing, and concrete age were considered as variable conditions to perform axial tension tests on roller compacted concrete (RCC) bidirectional induced joints. A finite element software was used for numerical simulation, and the simulation results were compared with the experimental results. The equivalent strength of the RCC induced joints increased with the spacing of the induced joints, but the rate of increase gradually declined. The equivalent strength of the RCC induced joints rapidly increased in the early stage, but the strength weakening degree was different at different concrete ages. The strength weakening degree of the induced joint section decreased as the concrete strength increased. These results provide a reference for the setting of induced joints in practical engineering.
\end{abstract}

\section{Introduction}

The roller compacted concrete (RCC) dam is a new dambuilding technology that combines the advantages of normal concrete dams and earth-rock dams [1-3]. Owing to the advantages of fast construction speed, high reliability, material saving, and low cost, RCC dams are widely used around the world $[4,5]$. However, in the constant construction of RCC arch dams, the temperature stress of the dam is caused by the temperature decrease in the late construction period and results in temperature cracking. To prevent the generation of temperature cracks, induced joints are generally used as a weak surface that is artificially constructed in dams. When the dam temperature decreases, the weak surface of the induced joint opens to dissipate the stress of the dam and control the development direction of the crack [6-8]. Therefore, the correct understanding of the forced state, fracture parameters, and suitable locations and sizes of the induced joints is of great significance for preventing the disorderly cracking of the dam.

Research on RCC arch dams has mainly focused on the structural form of the dam $[9,10]$, temperature control measures [11-13], and engineering applications [14-16]. There are relatively few studies on induced joints, which are generally introduced in practical engineering applications. Since the 1990s, experts and scholars in China have conducted a series of studies on cracking identification and the equivalent strength of induced joints. Zhang et al. [17] proposed the concept of the equivalent strength of induced joints. They pointed out that the equivalent strength of induced joints is the part of the strength that remains after the induced joint section is weakened, the strength of this 
section can reflect the induced joints of the field stress at fracture, and the equivalent strength variation can be obtained. Chen et al. [18] changed the reliability index calculation problem of a complex arch dam to a mathematical optimization problem and used a complex method to solve the problem and avoid the complex nonlinear performance function of derivative problems. By applying this method to the structural reliability analysis of the Shapai RCC arch dam, the distribution regularity of the Shapai arch dam and induced joint reliability index were obtained. Chen et al. [19] investigated the strength and fracture characteristics of the induced joints in a RCC dam and obtained the equivalent strength and fracture toughness of the induced joints by axial tension testing. By considering a large finite plate and a cylindrical arch dam with different spatial fracture surface shapes as examples, Chen et al. [20] obtained the equivalent stress intensity factor of the fracture surface using the virtual crack closure method and the Richard brittle fracture criterion and investigated the variation of the stress intensity factor with the angle of the fracture surface.

Based on the above research, this study considered the concrete strength, inducer spacing, and concrete age as variables. We compared and analyzed the simulation and test results obtained by the axial tension testing of a RCC bidirectional interval induced joint specimen and numerical simulation using a finite element calculation software.

\section{Experimental Design}

2.1. Experimental Materials and Mixing Proportions. In the experiment, we used water, P.O. 42.5 ordinary Portland cement, second class powdered coal ash, a coarse aggregate with a maximum diameter of $40 \mathrm{~mm}$, and medium sand with a fineness modulus of 2.5 . The silt content did not exceed $2 \%$. The admixture was the JC-04 effective naphthalene waterreducing agent, which was used to improve the cohesiveness and antisegregation of the RCC mixture. The RCC mixing proportions are listed in Table 1.

2.2. Design and Production of Specimens. The increase of the weakened area of the induced joints means that the connection area of the induced joints is further reduced. Therefore, the strength is also affected, which is unfavorable to the dam's stress-bearing capability. Therefore, the weakened area of the dam section should not be too large. Considering the fact that the equivalent strength of the induced joints is still relatively large in practical engineering, the equivalent strength can be further reduced by changing the concrete strength, inducer spacing, and concrete age. Studies have shown that the equivalent strength of the RCC induced joints increases with the inducer spacing, but the increase eventually tapers off. The equivalent strength of the RCC induced joints rapidly increases in the early stage, but the strength weakening degree is different at different ages. The weakening degree of the induced joint section decreases as the concrete strength increases. Therefore, this study considered the influences of the concrete strength, inducer spacing, and concrete age, and nonpenetrating RCC specimens with bidirectional spacing were prepared to simulate the practical bidirectional spacing of the induced joints of RCC dams.

According to the fracture mechanics theory, the stress intensity factor $K I$, which is related to the far-field stress, reserved joint size, and distance between adjacent joints, represents the strength of the crack tip stress. When KI reaches the unstable fracture toughness $K_{\text {Ic }}$ of the material, the crack begins to expand in an unstable manner. At this time, the far-field stress acting on the structure is the equivalent strength described in this paper. Liu et al. [21] established the equivalent stress criterion of the induced cracks by applying the Double $K$ Fracture Criterion and incorporated the result in the simulation of the stress field for the Shapai RCC Arch Dam. Additionally, they demonstrated that the double $K$ criterion is feasible in dam engineering. Zeng and $\mathrm{Ma}$ [22] used the method of linear elastic fracture mechanics (LEFM) to calculate the far-field stress of the induced fracture section when the fracture begins to grow unstably. Additionally, they considered the far-field stress as the equivalent strength of the induced fracture and established a functional relationship among the equivalent strength, fracture energy, and area weakening rate. Based on the concept of equivalent strength, the specimen is analogous to the actual induced joint of the arch dam. Because the height of the reserved joint is much smaller than the height of the dam body, it is reasonable to simplify the induced joint in the specimen as a reserved joint on an infinite flat plate. The layout and stress of the specimens are close to those of the actual induced joints of a dam; therefore, they can be analogized, and the obtained test results and laws can be applied to the layout of the induced joints of RCC arch dams.

The size of the test mold is designed and formulated in strict accordance with the "Test code for hydraulic concrete" (SL352-2006; China), and it is generally used around the world to test the concrete axial tension. The specimen size was $500 \mathrm{~mm} \times 150 \mathrm{~mm} \times 150 \mathrm{~mm}$, and the inducers were replaced by $2 \mathrm{~mm}$ thick rectangular steel plates (induction plates). The size of the inducers was $75 \mathrm{~mm} \times 25 \mathrm{~mm}$. Because one of the aims of this test is to investigate the effect of the inducer spacing on the equivalent strength, it is very important to fix the inducer positions. Therefore, the mold and inducers must be slightly modified. Two rows of holes were cut side by side in the inducer section of the mold, and four corner holes were drilled into the steel plate. According to the size of the inducers, the steel plate was connected with the hole of the mold and made to stand in the specimen perpendicular to the direction of the long side of the mold. The detailed layout is shown in Figure 1. The structural design of the specimen can effectively ensure that a local weakening surface is formed around the induction plate without affecting the concrete in the vicinity.

2.2.1. RCC Mixing Process. The RCC was prepared according to the pebble (coarse aggregate), sand, cement, and fly ash proportions listed in Table 1 . The sand and pebble contents were subject to the mass under the condition of a saturated dry surface. The weighing accuracy of the cement, 
TABLE 1: Mixing proportions of RCC used in bilateral interval induced joint test.

\begin{tabular}{lcccccc}
\hline Strength & Water $\left(\mathrm{kg} / \mathrm{m}^{3}\right)$ & Cement $\left(\mathrm{kg} / \mathrm{m}^{3}\right)$ & Fly ash $\left(\mathrm{kg} / \mathrm{m}^{3}\right)$ & Medium sand $\left(\mathrm{kg} / \mathrm{m}^{3}\right)$ & Coarse aggregate $\left(\mathrm{kg} / \mathrm{m}^{3}\right)$ & $\mathrm{Admixture}\left(\mathrm{kg} / \mathrm{m}^{3}\right)$ \\
\hline C20 & 130 & 90 & 110 & 784 & 1285 & 4 \\
C30 & 130 & 110 & 110 & 783 & 1283 & 4.6 \\
C40 & 130 & 130 & 130 & 710 & 1340 & 6 \\
\hline
\end{tabular}

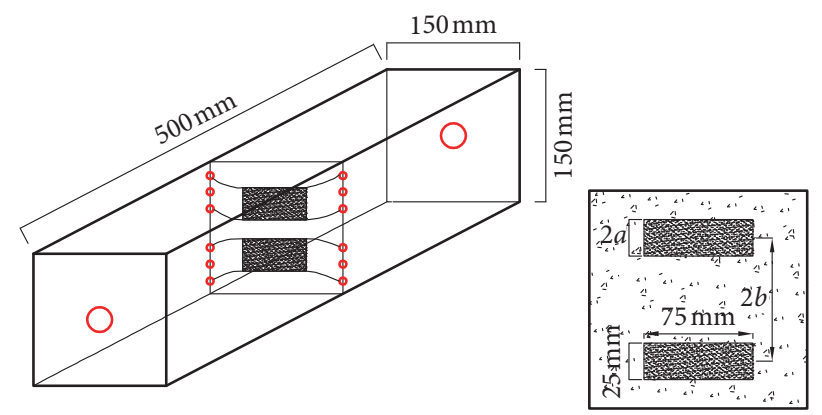

FIgURE 1: Arrangement of inducers.

water, and admixture were $\pm 0.3 \%$, and that of the coarse aggregate was $\pm 0.5 \%$. To prevent errors caused by uneven mixing in the stirring process, $150 \%$ of the required material should be weighed. The weighing materials were poured into the mixer and evenly mixed in advance. Then, the admixture and water were added to the mixer and mixed. The concrete mixture was thoroughly stirred and then poured into the mold.

2.2.2. Vibration and Maintenance of RCC. The inner wall of the specimen mold was cleaned, and a thin layer of mineral oil was applied. At the same time, the inducer was treated by wiping off the dirt on its surface, and a sufficient amount of mineral oil was applied. After adding the mixture, the RCC was placed on a shaking table. The mixture was continuously vibrated and compacted with a vibrating rod until the concrete surface was pulped. The vibration frequency of the shaking table was controlled at approximately $50 \pm 3 \mathrm{~Hz}$, and the amplitude was $0.5 \pm 0.1 \mathrm{~mm}$. After the vibration, the results obtained by the equivalent strength test for the induced joints of the RCC were more accurate owing to the better compacting effect. A spatula was used to make the RCC specimen flush with the mold mouth. Finally, the molded specimen was removed after being placed in a standard curing room for $72 \mathrm{~h}$.

The process of specimen fabrication is shown in Figure 2.

\subsection{Experimental Measurements and Data Acquisition. A} WAW-3000C microcomputer-controlled servo universal testing machine was used to carry out the axial tensile test of the specimen. The universal testing machine was equipped with a controller, measuring software, and other devices. The controller integrates the force measurement channel, deformation measurement channel, and multiple input digital quantity interfaces for detection and control. The measurement software can automatically obtain the data, carry out processing and data testing, and display the various test curves in real time with high accuracy. To more accurately determine the crack sizes, a YYJ-4/10 electronic extensometer was used in the test. The universal testing machine is shown in Figure 3.

During the test, the axial deformation value at the induced joint section, load value on the induced joint concrete specimen, and intermediate displacement of the crack were recorded. The test measurement method was carried out as follows:

(1) The correctness of the line connection was checked, and the control of the electrohydraulic servo universal testing machine by the WAW-3000C microcomputer was subsequently initiated.

(2) First, the sleeve was rotated to pull the rod at both ends of the specimen to confirm that it was firmly connected. Next, the universal testing machine was lifted to a suitable height for the setting of the specimen. The specimen was fixed to the upper nip seat and lower nip seat of the universal testing machine by a bolt. Before the test started, it was confirmed that the specimen had been fixed.

(3) In the measurement and control software, the singlestep control mode was used to set the control speed. The control mode was set to the test force with a control speed of $0.15 \mathrm{kN} / \mathrm{s}$, and the target mode was set to the test force with a target value of $3000 \mathrm{kN}$. The sample information was filled in, basic information such as the test batch number and specimen size was edited, and a new test number was created.

(4) The axial tensile test was initiated, and the test curve was observed during the test. The test stopped when the test curve exhibited the instantaneous decrease of the test force from the maximum value, and an obvious brittle fracture sound was heard. During the 


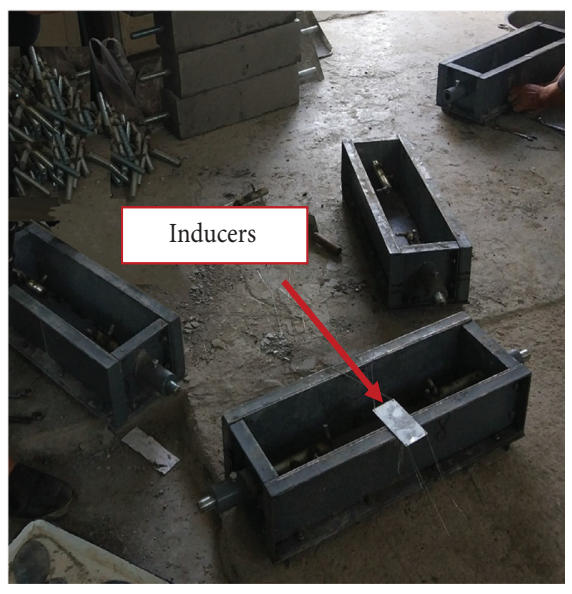

(a)

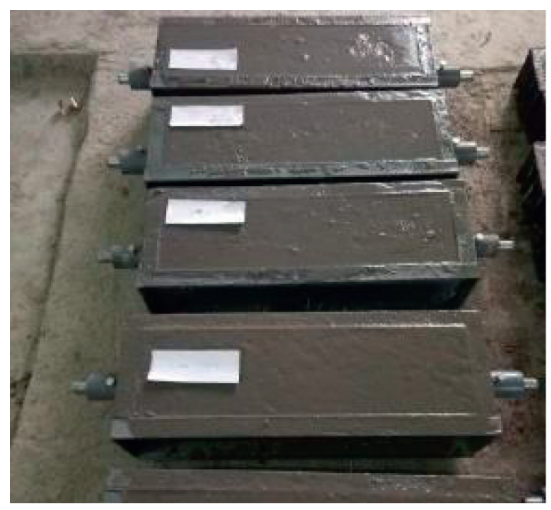

(d)

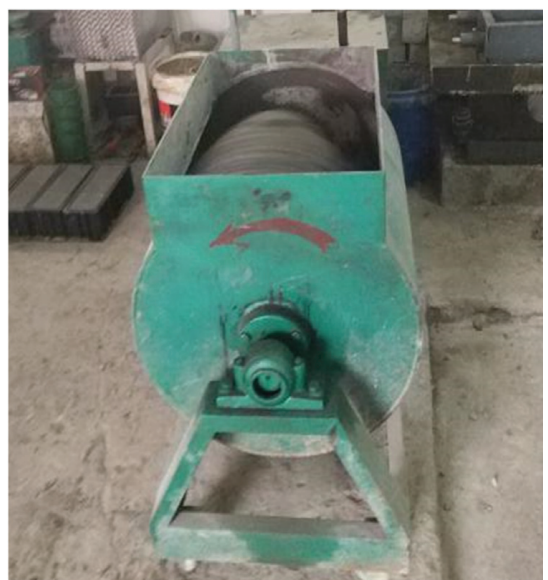

(b)

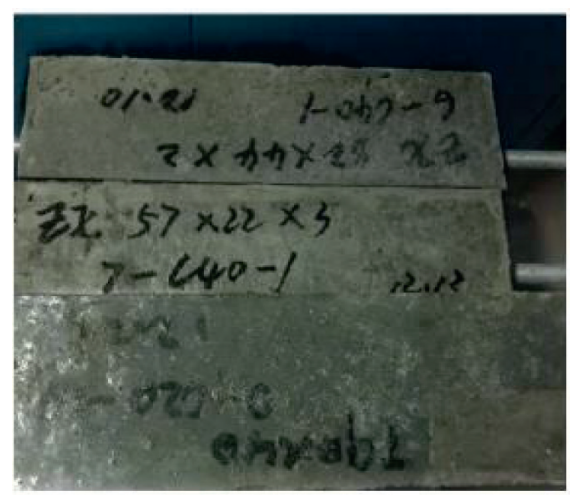

(e)

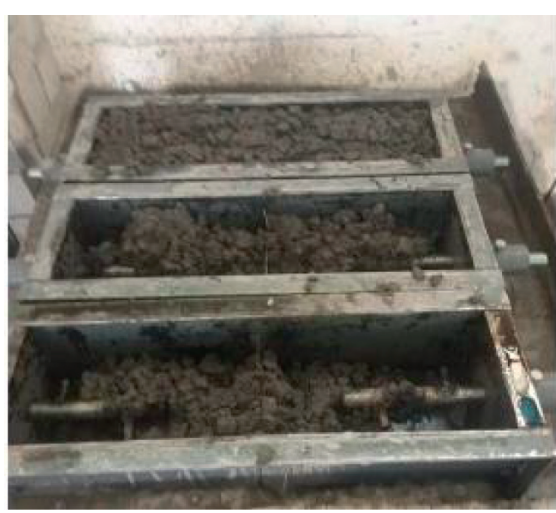

(c)

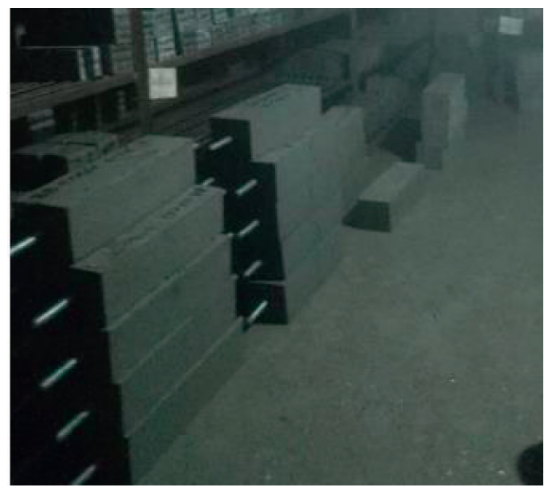

(f)

Figure 2: Flow chart of RCC specimen fabrication, (a) assembly, (b) mixing, (c) charging, (d) trowel finish, (e) form removal, (f) maintenance.

test, a high-speed camera was used to capture the instantaneous fracture of the specimen.

(5) The maximum test force, axial tension, and axial displacement were recorded by the universal testing machine.

\section{Analysis of Equivalent Strength Test Results for RCC Induced Joints}

3.1. Test Results. In the specimen design, the influence of the concrete strength (C20, C30, and C40 concrete), inducer spacing $(s=10,20,30,40,50$, and $60 \mathrm{~mm})$, and concrete age (7, 14, 28, 60, and 90 days) was considered, and 14 specimen groups (three in each group) were prepared to obtain a total of 42 specimens.

3.2. Analysis of Test Failure Phenomenon. During the test, the universal testing machine was controlled to apply an axial test force to the specimen at a speed of $0.15 \mathrm{kN} / \mathrm{s}$, and the high-speed camera was turned on to photograph the fracture instant during the test. When the brittle fracture of the specimen occurred, an obvious fracture sound was heard, and the test force curve collected by the testing machine was observed to instantaneously decrease from the maximum value. The image captured at the moment of fracture by the high-speed camera is shown in Figure 4 . The brittle fracture occurred within a very short amount of time; therefore, several representative pictures were selected to describe it. As the load increased, small cracks gradually appeared in the section when the tensile stress of the specimen was greater than the tensile strength of the section at the induced joint location, and the cracks began to break in an unstable manner, which means that the stress intensity factor of the induced joint reached the fracture toughness value of the concrete material, as shown in Figures 4(a) and 4(b). Then, the small cracks gradually expanded into cracks, as shown in Figure 4(c). The crack width further increased, the concrete connection area gradually decreased, fine concrete fragments fell off the edge of the specimen during the tensile cracking, and the specimen finally exhibited instant tensile cracking, as shown in Figures 4(d)-4(f).

\subsection{Analysis of Test Result}

3.3.1. Relationship between Equivalent Strength of Induced Joints and Concrete Strength. From Table 2, it can be seen that the equivalent strength of the RCC induced joints increased with the concrete strength, and the strength 


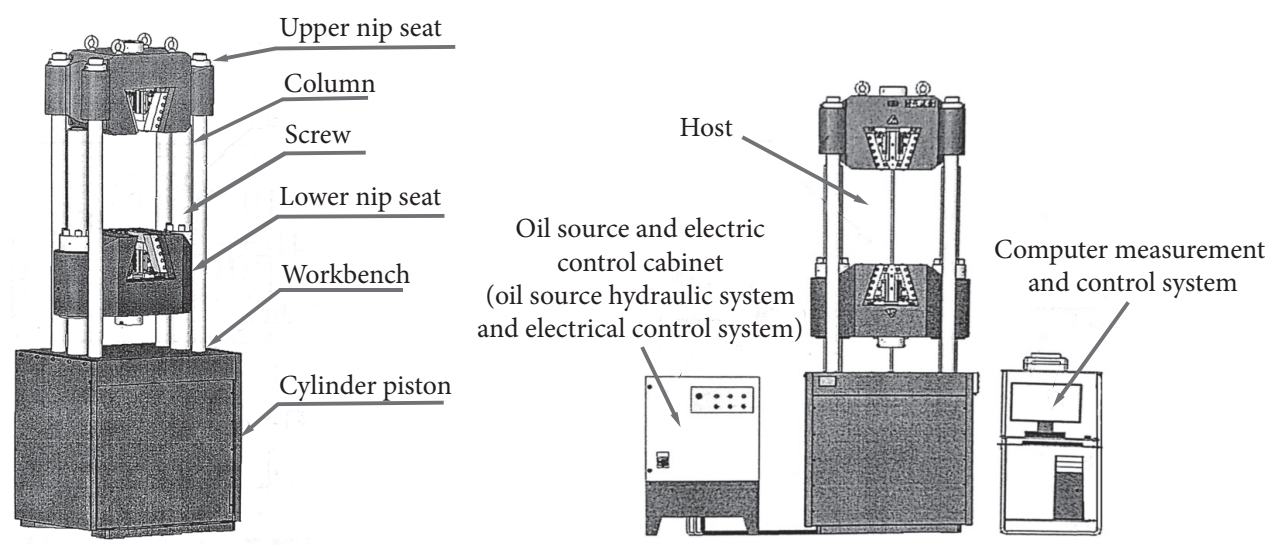

FIgURE 3: Universal testing machine.

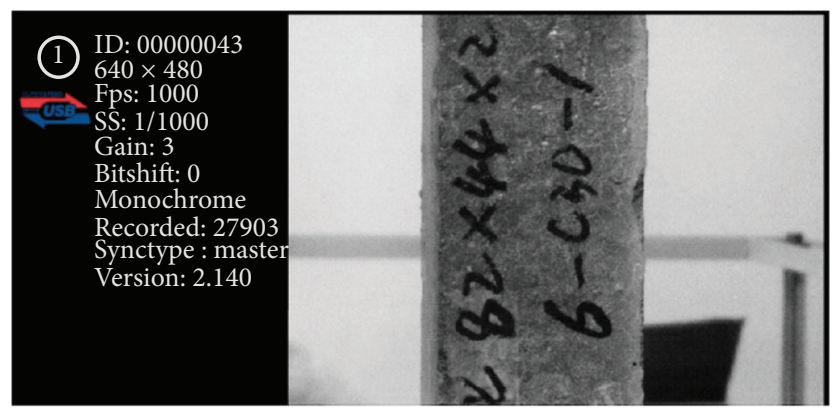

(a)

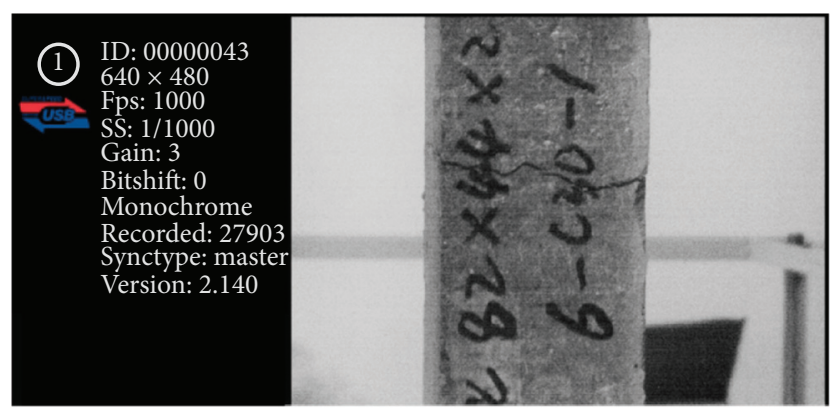

(c)

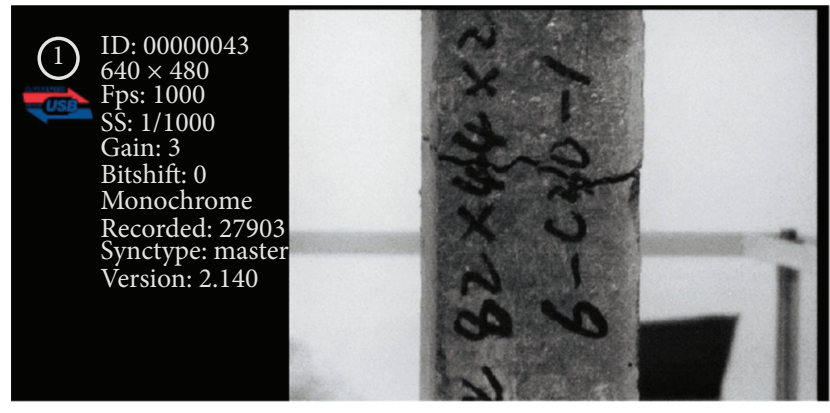

(e)

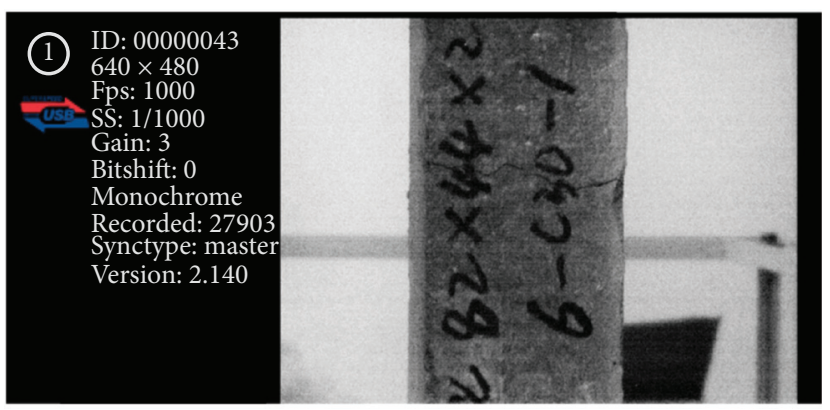

(b)

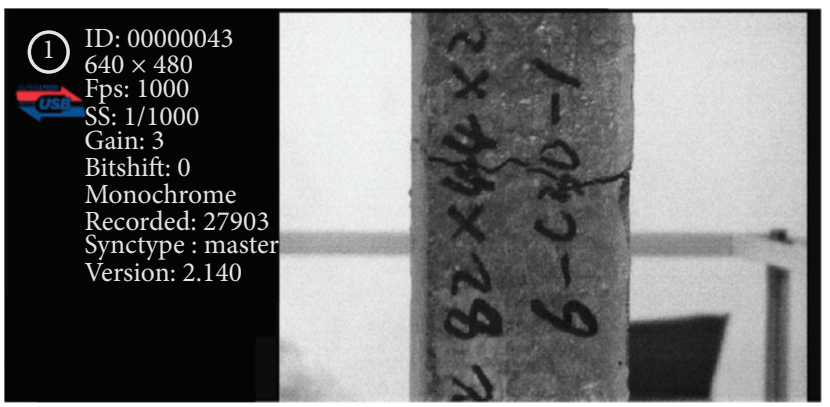

(d)

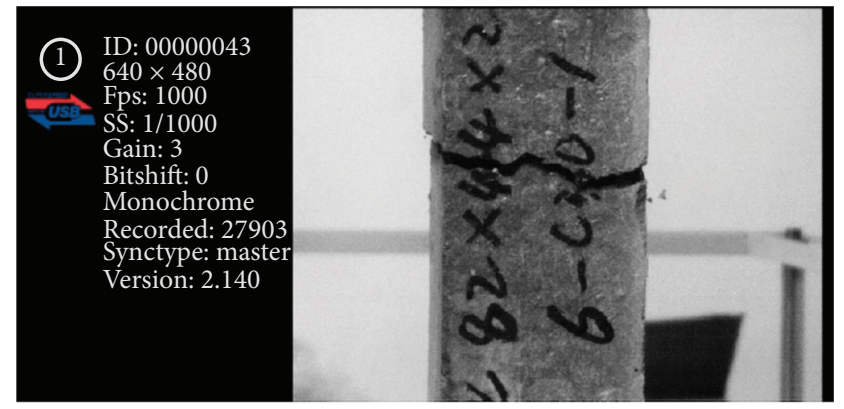

(f)

Figure 4: Photograph of instantaneous fracture captured by high-speed camera. 
TABLE 2: Summary of equivalent strength test results for different concrete strengths.

\begin{tabular}{|c|c|c|c|c|c|c|}
\hline Inducers form & $\begin{array}{l}\text { Specimen size } \\
L \times n \times \mathrm{m}(\mathrm{mm})\end{array}$ & Number & $\begin{array}{l}\text { Age } \\
\text { (day) }\end{array}$ & $\begin{array}{l}\text { Space } \\
(\mathrm{mm})\end{array}$ & $\begin{array}{l}\text { Average load } \\
(\mathrm{kN})\end{array}$ & $\begin{array}{l}\text { Equivalent strength average } \\
(\mathrm{MPa})\end{array}$ \\
\hline \multirow{14}{*}{$\begin{array}{l}\text { Bidirectional interval nonpenetration } \\
\text { induced joints }\end{array}$} & \multirow{14}{*}{$500 \times 150 \times 150$} & $1-\mathrm{C} 20-90$ & \multirow{3}{*}{90} & \multirow{3}{*}{20} & 28.733 & 1.277 \\
\hline & & $1-\mathrm{C} 30-90$ & & & 41.009 & 1.823 \\
\hline & & $1-C 40-90$ & & & 53.350 & 2.371 \\
\hline & & $2-\mathrm{C} 20-28$ & \multirow{6}{*}{28} & 10 & 24.758 & 1.073 \\
\hline & & $2-C 20-28$ & & 20 & 24.935 & 1.094 \\
\hline & & $2-C 20-28$ & & 30 & 25.632 & 1.144 \\
\hline & & 2-C20-28 & & 40 & 26.836 & 1.164 \\
\hline & & $2-\mathrm{C} 20-28$ & & 50 & 27.011 & 1.179 \\
\hline & & $2-\mathrm{C} 20-28$ & & 60 & 27.192 & 1.184 \\
\hline & & 3-C20-7 & 7 & & 10.148 & 0.451 \\
\hline & & $3-\mathrm{C} 20-14$ & 14 & & 20.231 & 0.740 \\
\hline & & $3-\mathrm{C} 20-28$ & 28 & 20 & 24.593 & 1.093 \\
\hline & & $3-\mathrm{C} 20-60$ & 60 & & 26.528 & 1.179 \\
\hline & & $3-\mathrm{C} 20-90$ & 90 & & 28.733 & 1.277 \\
\hline
\end{tabular}

weakening degree of the induced joint section slightly decreased as the concrete strength increased. In other words, as the strength grade of the concrete increased, the weakening of the concrete became more difficult.

The test results reveal that concrete with different strength grades should be used in various parts of the dam to satisfy the stress requirements. For the parts of the dam with larger stress, concrete with higher strength is typically used to increase the safety margin of the dam. Because the equivalent strength of the concrete increases as the strength grade increases, the stress at the induced joint section may not increase; therefore, the induced joints do not crack.

\subsubsection{Relationship between Equivalent Strength of Induced} Joints and Spacing of Induction Plates. In the test, there was a large difference between the spacing of the induction plates and the actual induced joints of an arch dam; therefore, it was difficult to make an accurate comparison. Hence, the spacing of the induction plates was considered according to the ratio of the distance between the center of the short axis of the adjacent induction plate $2 b$ and the height of induction plate $2 a$. The induction plate spacing was set to 10 , $20,30,40,50$, and $60 \mathrm{~mm}$, and the corresponding $b / a$ values were 1.4, 1.8, 2.2, 2.6, 3, and 3.4, respectively. According to the experimental data, the relationship between the spacing of the C20 RCC induction plates and the equivalent strength was obtained by fitting with equation (1); the fitting curve is shown in Figure 5. The spacing of the inducers is expressed as $b / a$. After fitting, it was found that the curves obtained by simple linear, logarithmic, and exponential fitting had low Goodness-of-Fit. Therefore, the more reasonable equation of $y=m+n \times p^{x}$ was chosen for fitting by the data processing software. The $R^{2}$ was 0.952 , which indicates a good fitting relationship that can accurately explain the correlation of the data.

$$
f_{e q}=1.2255-0.43735 \times 0.48427^{b / a}, R^{2}=0.952 .
$$

As can be seen in Figure 5, as the spacing of the induction plates increased, the equivalent strength of the induced joints with the same weakening degree and induction plate size also increased, but the increase amplitude gradually decreased. At the same time, the equivalent strength also increased with the displacement. When the spacing was $60 \mathrm{~mm}$, the strength of the concrete body that was weakened by the induction plate was only $29.65 \%$. When the spacing decreased to 40 and $20 \mathrm{~mm}$, the weakening degree increased to $31.67 \%$ and $35.51 \%$, respectively.

The test results reveal that, in practical engineering, a suitable induced joint arrangement can more effectively reduce the equivalent strength of the induced joints compared with simply increasing the weakening degree, which indicates the direction for improving the design level of the induced joints. In view of the high weakening degree of induced joints in current engineering, increasing the weakening degree of induced joints to reduce the equivalent strength is not conducive to the transfer of stress at the induced joint section.

\subsubsection{Relationship between Equivalent Strength of Induced} Joints and Concrete Age. The RCC strength gradually increased with the age, and the strength and age are closely related. To investigate the effect of the concrete age on the equivalent strength, the different curing ages of $7,14,28,60$, and 90 days were set to control the weakening degree, number of induction plates, and spacing of the induction plates. From the experimental data, the relationship between the variation of the equivalent strength of the RCC induced joints at different ages was obtained (Equation (2)), and the fitting curve is shown in Figure 6. Through fitting, it was found that the curves obtained by simple linear, logarithm, and exponential fitting had low Goodness-of-Fit. Hence, the more reasonable formula of $y=m+n \times p^{x}$ was chosen for fitting using the data processing software. The $R^{2}$ was 0.99032 , which indicates a good fitting relationship that can accurately explain the correlation of the data. 


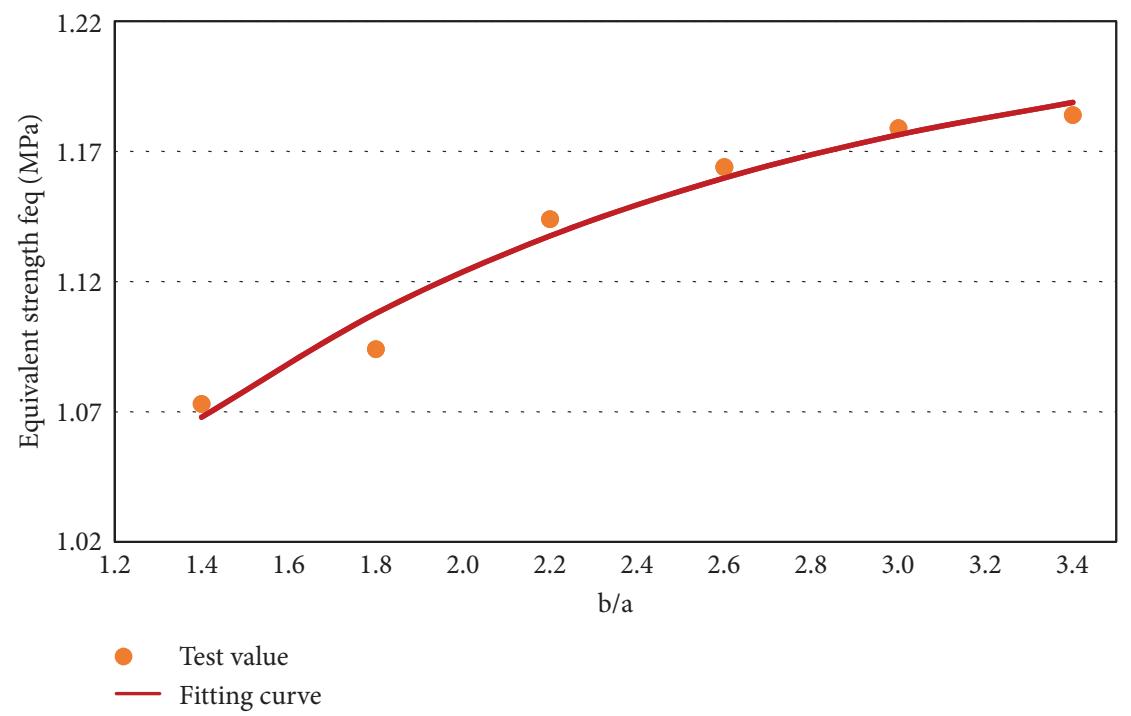

FIGURE 5: Fitting curve of relationship between equivalent strength of induced joints and inducer spacing.

$$
f_{\text {eq }}=1.24604-1.31612 \times 0.93153^{t}, R^{2}=0.99032 .
$$

As can be seen in Figure 6, the equivalent strength of the induced joints rapidly increased in the early stage but slowed down after 28 days. The equivalent strengths after 28 and 60 days were $85 \%$ and $92 \%$ of that after 90 days, respectively. This also confirms the importance of performing the experiment for 90 days. For the RCC, most of the relevant strength parameters provided in this paper are the values obtained after 90 days. At this time, the RCC strength increased but the increase rate was slow, which made it easier to obtain accurate correlation rules. The trend of the equivalent strength increase of the RCC induced joints was approximately the same as the concrete tensile strength, but there was a difference in the degree of strength weakening. For the early age, the degree of strength weakening was significantly higher than that for other concrete ages and gradually decreased as the concrete age increased. It is understood that the variation of the induced joint equivalent strength of the RCC arch dam determines its development process. The equivalent strength of the induced joints and the cracking time can be predicted based on the correlation between the tensile strength and the degree of weakening of the RCC at different concrete ages.

\section{Numerical Simulation of Equivalent Strength of RCC Induced Joints}

4.1. RCC Induced Joint Calculation Model. The Abaqus finite element software was used to establish the model, perform numerical simulation for each scheme, investigate the stress state of the induced joint section, understand the fracture process of the specimen, and verify the reliability and accuracy of the equivalent strength model established by the test. According to the actual RCC induced joint specimen used to establish the model, the coordinate origin was located at the bottom center of the specimen, the $X$ and $Y$ axes extended to both sides of the bottom surface, the long axis direction of the specimen was the $Z$-axis direction, and the pointing direction was the positive direction. The induction plate was simulated by hollowing out the central section of the specimen to each side by $1 \mathrm{~mm}$ (1/2 of the thickness of the induction plate). To more accurately simulate the axial tensile test of the actual induced seam specimen, two steel reinforcement bars with a diameter of $16 \mathrm{~mm}$ were embedded into the concrete specimens at the upper and lower central points of the concrete specimens, and test loads were applied to the two steel bars. The model was divided into 89,253 units and 127,855 nodes using 10-node quadratic tetrahedral elements (C3D10). The material model was a linear elastic model, and the $\rho$ of concrete was $2400 \mathrm{~kg} / \mathrm{m}^{3}$; binding contact was adopted as the property of the interface between the steel rod and the concrete. The calculation model is shown in Figure 7.

4.2. Analysis of Numerical Simulation Results. The elastic modulus changed with the age. When the test specimens were simulated with different ages, according with the curve of the change of the elastic modulus with time, the finite element software was used to calculate the elastic modulus values for different ages. According to the test mixing ratio data, the elastic modulus values of the C20, C30, and C40 concrete were $26.5,32.5$, and $36.4 \mathrm{GPa}$, respectively, and Poisson's ratio was 0.2 .

When the loading process was simulated, it was necessary to apply the load to the tie rods on both sides of the model for axial stretching in strict accordance with the loadtime curve obtained by the test. The test load curve was discretely measured with a time step of $1.0 \mathrm{~s}$. When the load was applied, the time and load were read into the "load" module for calculation, and the other four faces were set as free boundaries. When the load reached the maximum load, the stress nephogram of the induced joint section was analyzed, and the stress distribution was determined. The 


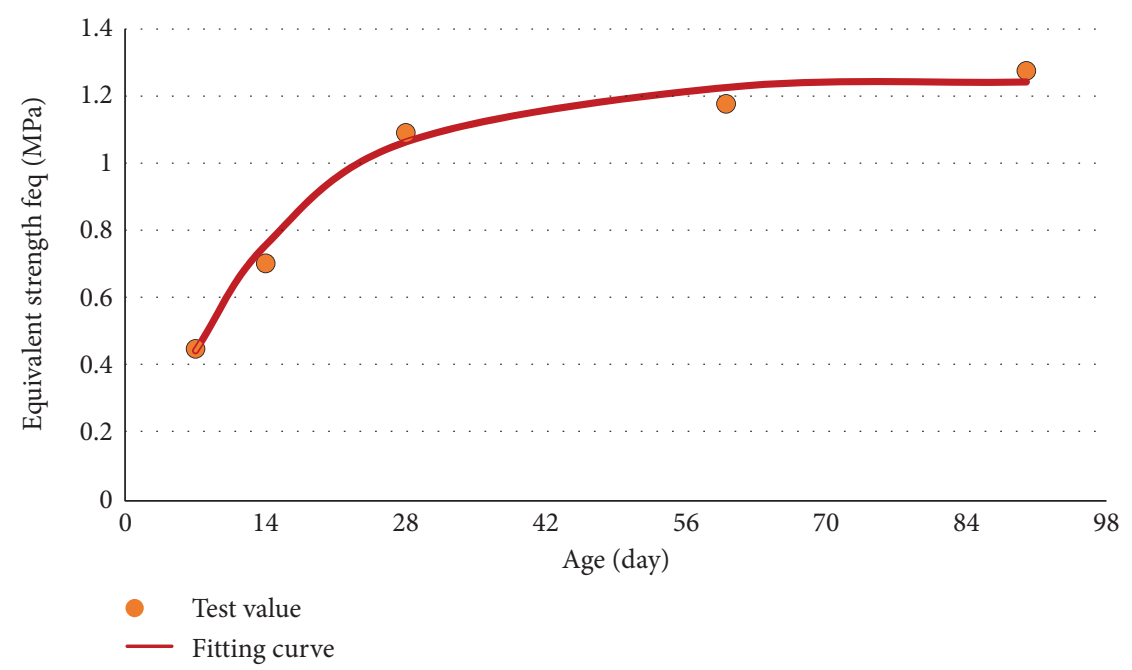

FIGURE 6: Fitting curve of relationship between equivalent strength of induced joints and curing age.

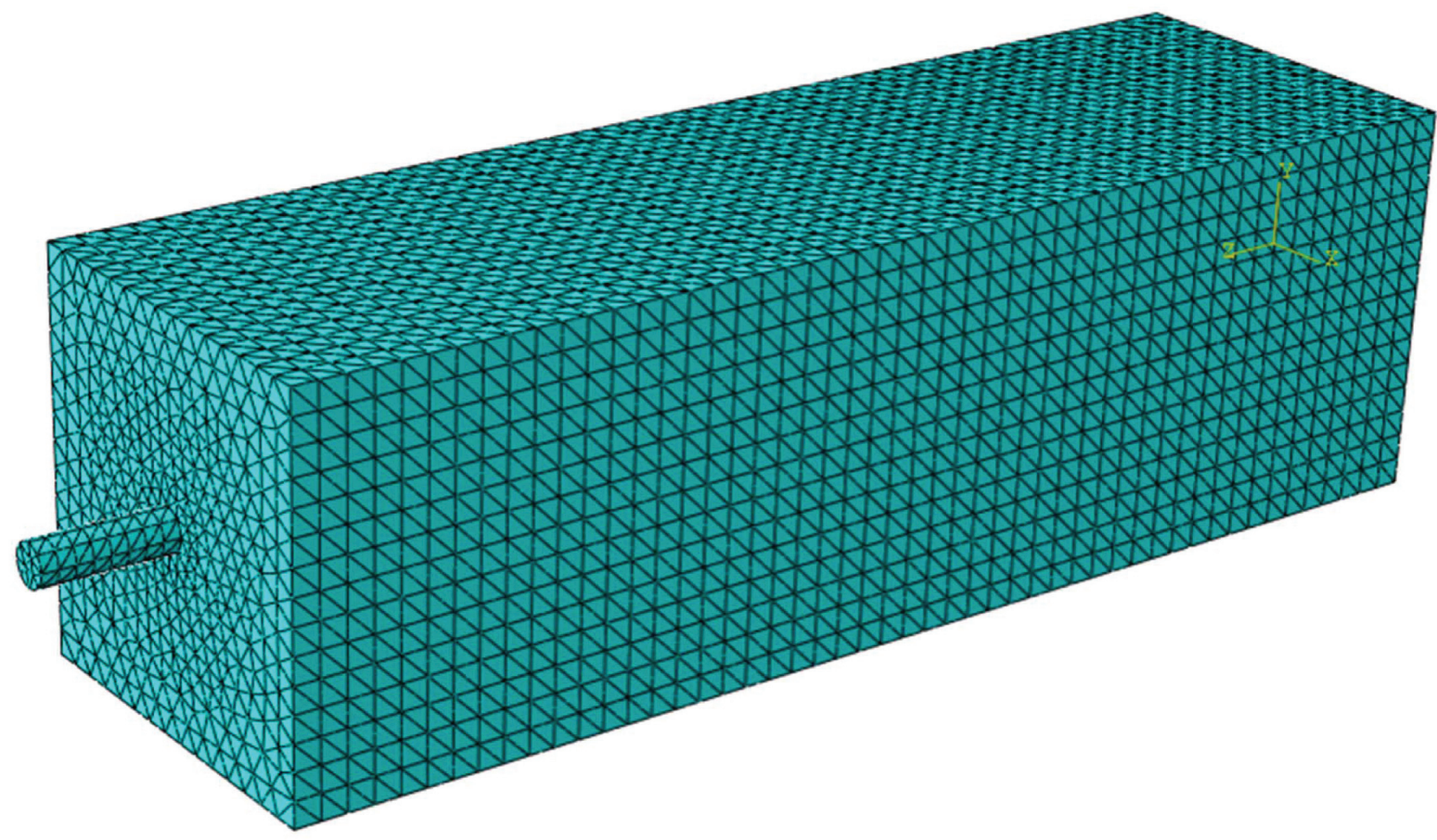

Figure 7: RCC induced joint simulation model.

calculated overall stress nephograms with different variables are shown in Figures 8-10.

As can be seen in Figures 8-10, the highest stress was concentrated on the long and short sides of the induction plate and gradually decreased from the inner side to the outer side along the four sides of the induction plate. When the load gradually increased, a crack started to form from the four sides of the induction plate, expanded to become stable, and gradually accumulated energy. During the crack stability expansion process, the energy released by the crack end region was used to form a new crack area. This state was a quasistatic situation. As the load further increased, when the release energy was greater than the energy required to form the crack area, an unstable fracture occurred; that is, the specimen underwent brittle fracture. In the cracking process, the induced joint as an artificial crack underwent a cracking process that consisted of crack initiation, stable expansion, and instability, in the same manner as natural cracks.

When designing the test plan, if the induction plate is placed close to the edge of the specimen, it may be affected by the 


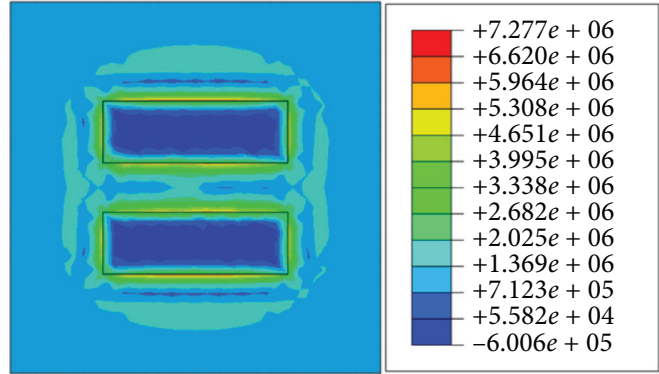

(a)

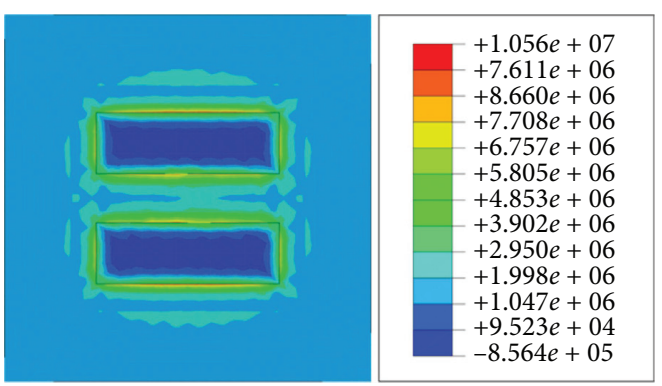

(b)

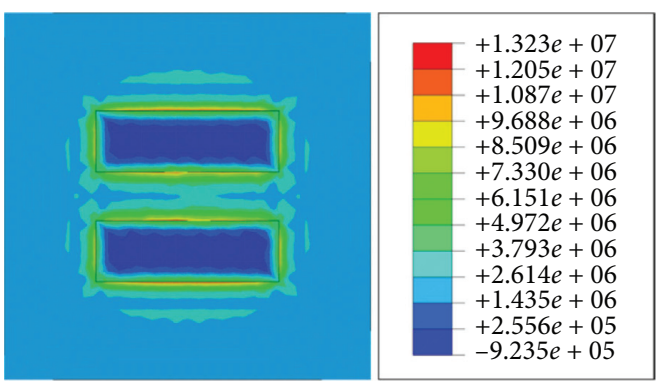

(c)

Figure 8: Simulated stress nephograms of RCC induced joint specimens with different concrete strengths (Pa), (a) C20-90 (C20 concrete), (b) C30-90 (C30 concrete), (c) C40-90 (C40 concrete).

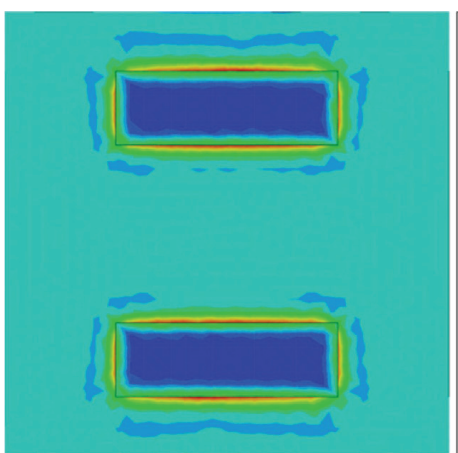

(a)

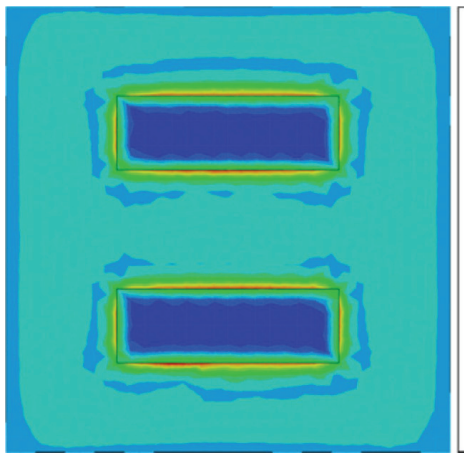

(c)
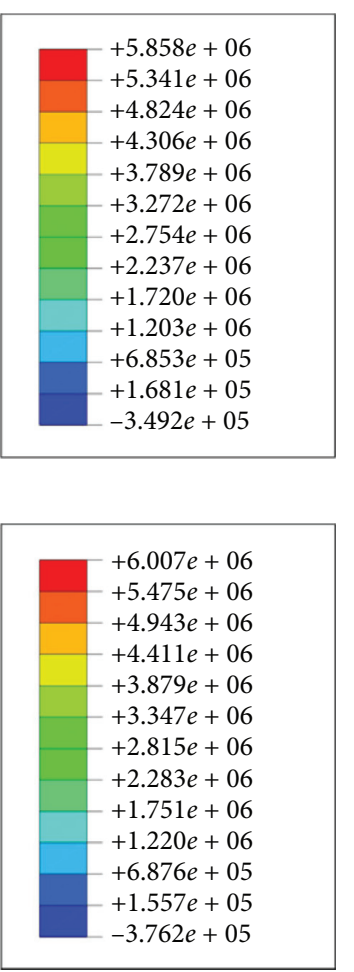

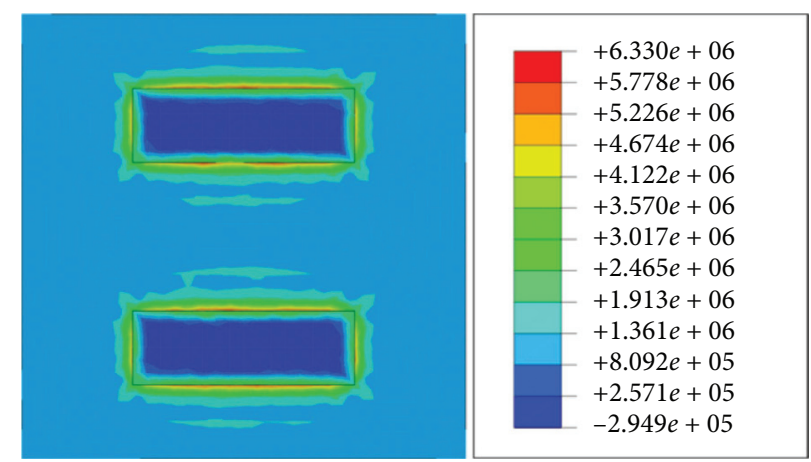

(b)

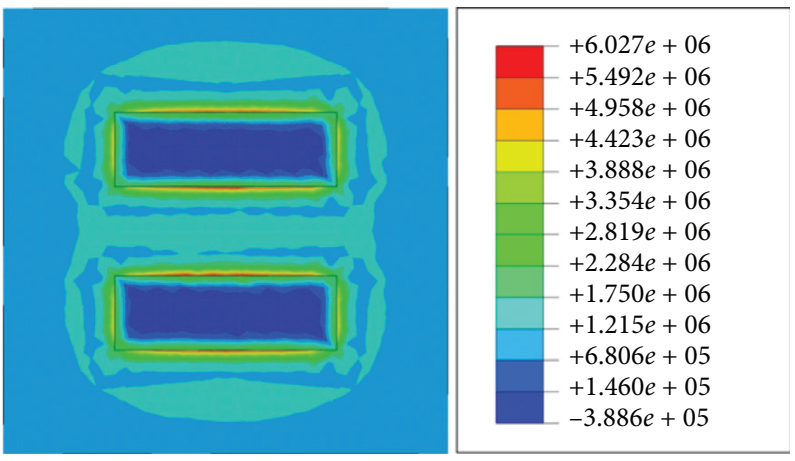

(d)

Figure 9: Continued. 


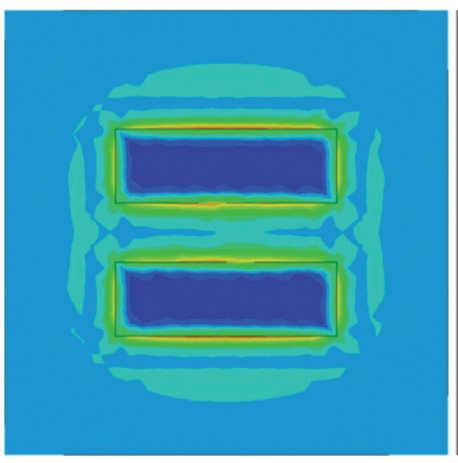

(e)

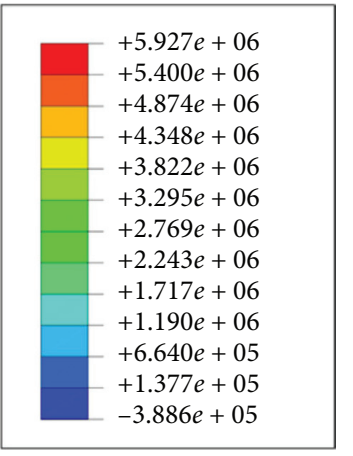

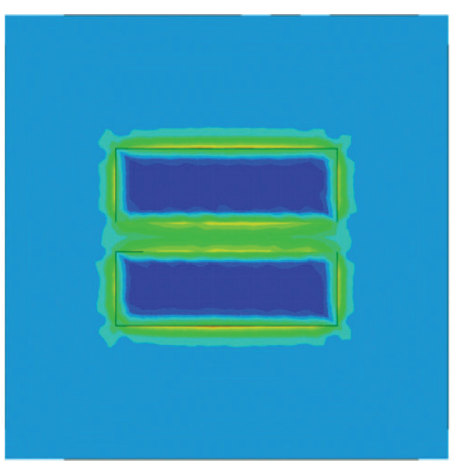

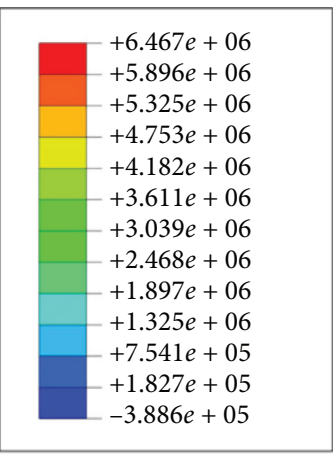

(f)

FiguRE 9: Simulated stress nephograms of RCC induced joints with different induction plate spacings (Pa), (a) C20-28 (b/a=3.4), (b) C20$28(b / a=3),(\mathrm{c}) \mathrm{C} 20-28(b / a=2.6),(\mathrm{d}) \mathrm{C} 20-28(b / a=2.2)$, (e) C20-28 (b/a=1.8), (f) C20-28 (b/a=1.4).

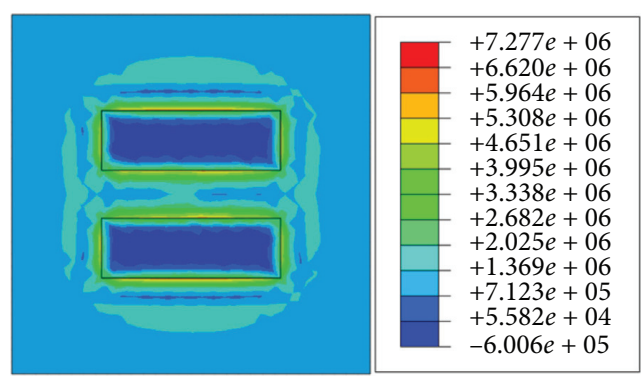

(a)

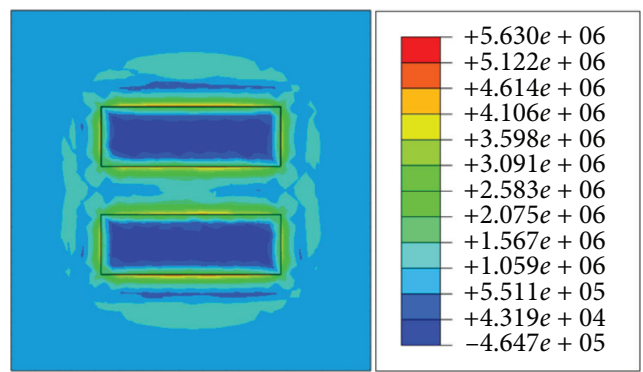

(c)

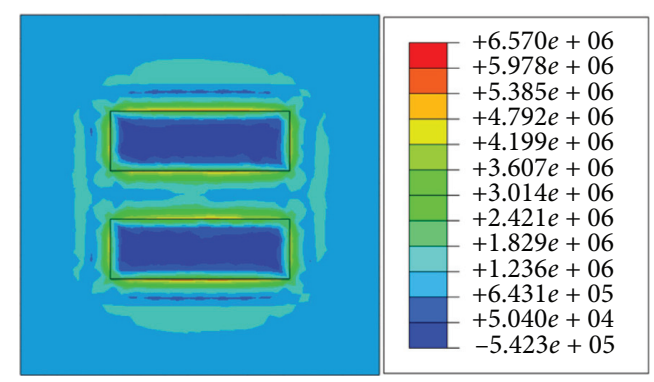

(b)

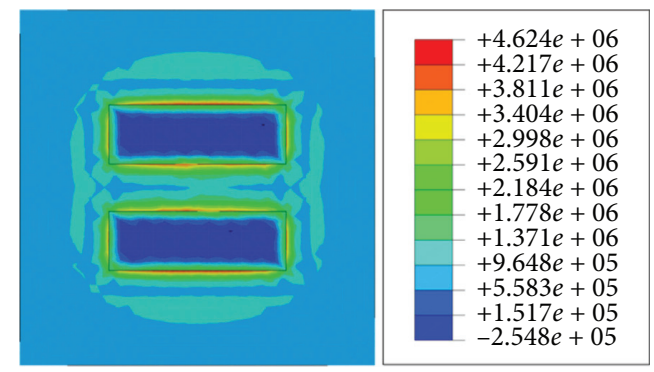

(d)

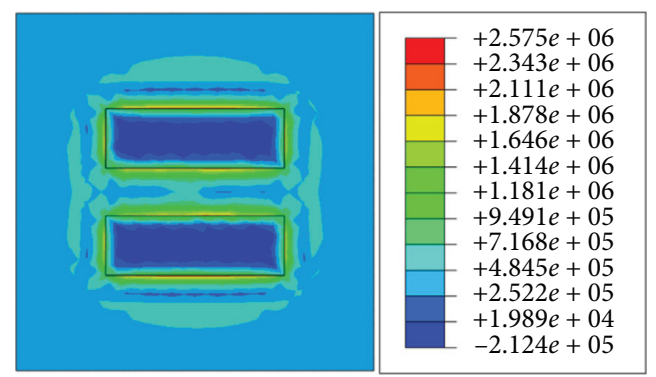

(e)

Figure 10: Simulated stress nephograms of RCC induced joints for different ages (Pa), (a) C20-90 (age of 90 days), (b) C20-60 (age of 60 days), (c) C20-28 (age of 28 days), (d) C20-14 (age of 14 days), (e) C20-7 (age of 7 days).

boundary and cause errors. The induction plate was determined to be no more than $20 \mathrm{~mm}$ from the edge of the specimen. From the stress cloud map, the stress value can be determined using the finite element software's query value function. Thus, it was found that the stress at the edge of the specimen was not affected, and the distance of $20 \mathrm{~mm}$ was reasonable. 
TABLE 3: Statistical table of equivalent strength test values, simulated values, and error values.

\begin{tabular}{|c|c|c|c|c|c|}
\hline Number & $\begin{array}{l}\text { Induced plate spacing } \\
(\mathrm{mm})\end{array}$ & Age (day) & Test value (MPa) & Simulation value $(\mathrm{MPa})$ & Error value (\%) \\
\hline $1-\mathrm{C} 20-90$ & 20 & 90 & 1.251 & 1.291 & 3.20 \\
\hline $1-\mathrm{C} 30-90$ & 20 & 90 & 1.823 & 1.836 & 0.71 \\
\hline $1-\mathrm{C} 40-90$ & 20 & 90 & 2.371 & 2.399 & 1.18 \\
\hline $2-\mathrm{C} 20-28$ & 10 & 28 & 1.073 & 1.106 & 3.12 \\
\hline $2-\mathrm{C} 20-28$ & 20 & 28 & 1.094 & 1.142 & 3.74 \\
\hline $2-\mathrm{C} 20-28$ & 30 & 28 & 1.144 & 1.185 & 3.56 \\
\hline $2-\mathrm{C} 20-28$ & 40 & 28 & 1.164 & 1.203 & 3.33 \\
\hline $2-\mathrm{C} 20-28$ & 50 & 28 & 1.179 & 1.223 & 3.69 \\
\hline $2-\mathrm{C} 20-28$ & 60 & 28 & 1.184 & 1.228 & 3.73 \\
\hline $3-\mathrm{C} 20-7$ & 20 & 7 & 0.451 & 0.489 & 8.43 \\
\hline $3-\mathrm{C} 20-14$ & 20 & 14 & 0.740 & 0.781 & 5.54 \\
\hline $3-\mathrm{C} 20-28$ & 20 & 28 & 1.093 & 1.187 & 8.60 \\
\hline $3-C 20-60$ & 20 & 60 & 1.179 & 1.234 & 4.66 \\
\hline 3-C20-90 & 20 & 90 & 1.277 & 1.321 & 3.45 \\
\hline
\end{tabular}

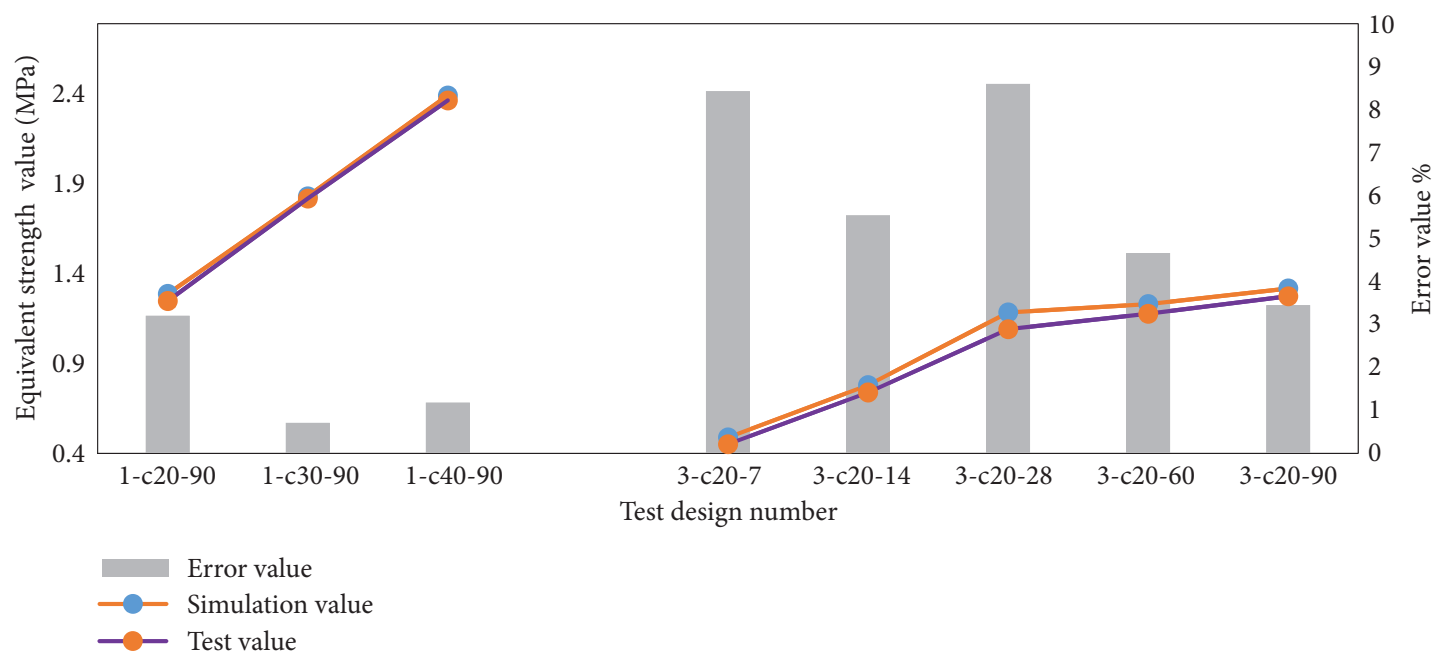

FiguRE 11: Induced joint equivalent strengths for different concrete strengths, age relationship test values, simulated values, and error value bar and line charts.

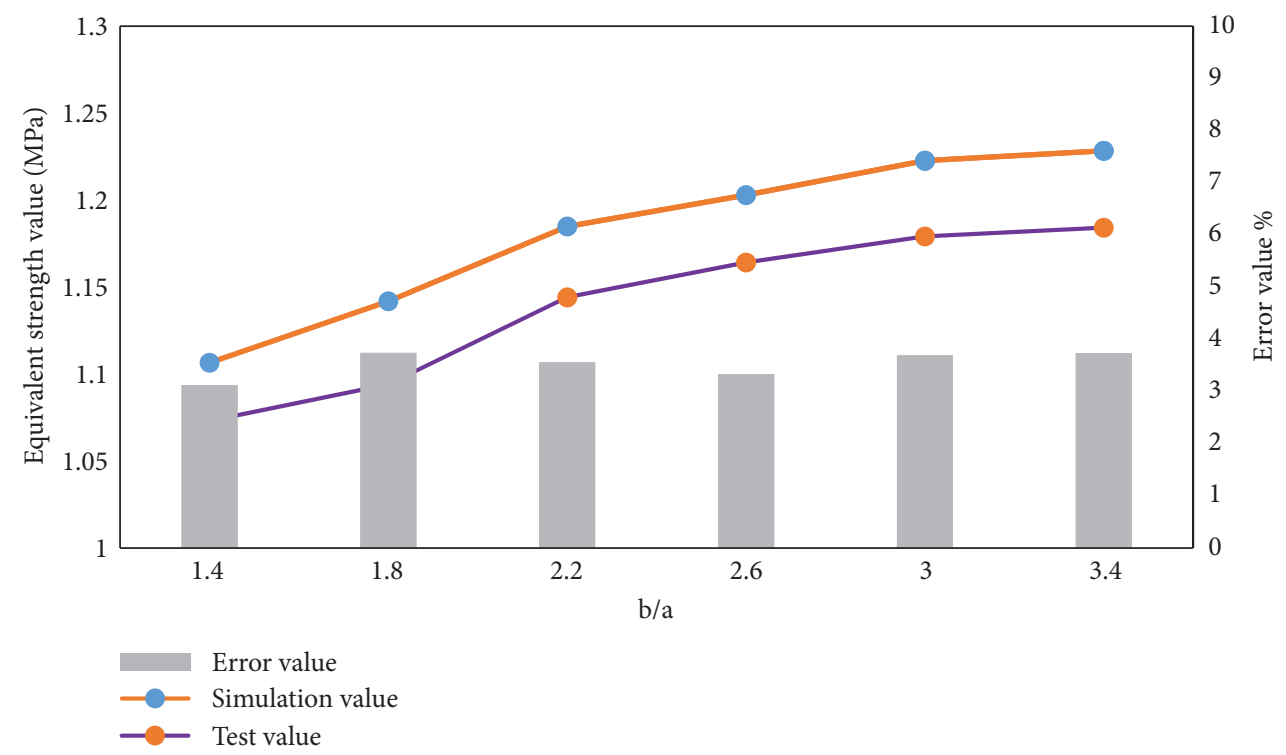

FIGURE 12: Relationships between experimental and simulated equivalent strength of induced joints and spacing, and error value bar chart. 
4.3. Comparative Analysis of Experimental and Simulation Results for RCC. Through the simulation of each scheme, the stress distribution state and simulated equivalent strength value of the induced joint section fracture were obtained. The experimental values obtained by the axial tensile testing of the RCC induced joint were compared with the simulation results, and the data error was determined to verify whether the selection of the simulated test parameters was correct and reasonable, and whether the equivalent intensity change law was consistent under each factor. The test value, simulation value, and error value for each scheme are listed in Table 3.

To more intuitively compare the trend and error range of the analog values, bar and line charts were constructed (Figures 11 and 12).

From Figures 11 and 12, the following conclusions can be drawn: (1) the equivalent strength of the induced joints increased with the spacing of the induction plates, and the increase rate gradually declined; (2) the equivalent strength of the RCC induced joint specimens at 28 and 60 days reached $89 \%$ and $94 \%$ of the final equivalent strength, which is different from the test results because the elastic modulus values for different ages of the model are different from those of the actual test, but the overall trend is essentially the same; (3) as the concrete strength grade improved, the equivalent strength of the induced joints increased and was consistent with the increase of the concrete strength.

The simulated values are consistent with the equivalent strength variation of the experimental values, and the data error range is less than 9\%. Accordingly, the parameters selected for the numerical calculation model are reasonable and reliable, and the equivalent strength model established by the test was verified. The test results and related changes are essentially correct.

\section{Conclusions}

In this study, the factors influencing the equivalent strength of the induced joints of RCC arch dams were investigated. Based on axial tensile testing, finite element software was used to investigate the stress distribution state and fracture process of the induced joint section. The simulation results were compared with the experimental results for verification. The following main conclusions were drawn from the experimentally obtained trend:

(1) The equivalent strength of the RCC induced joint increased with the tensile strength of the concrete body. The degree of weakening of the strength of the induced joint section slightly decreased as the concrete strength increased; that is, the weakening of the concrete was more difficult with a higher concrete strength grade.

(2) The equivalent strength of the RCC induced joints increased with the induction plate spacing, but the increase rate gradually declined.

(3) The equivalent strength of the induced seam rapidly increased in the early stage. The trend of increase of the equivalent strength of the induced joints was approximately the same as the concrete bulk tensile strength, but the degree of strength weakening was different. The degree of strength weakening at a small concrete age was significantly higher compared with that of other concrete ages and gradually decreased as the concrete age increased.

(4) The error between the experimental data and the simulated values did not exceed $9 \%$, which indicates that the test results and related changes are essentially correct.

\section{Data Availability}

The data used to support the findings of this study are available from the corresponding author upon request.

\section{Conflicts of Interest}

The authors declare that there are no conflicts of interest regarding the publication of this paper.

\section{Acknowledgments}

This study was financially supported by the National Nature Science Foundation of China (Nos. 51479168 and 51579208). The authors thank Tim Cooper, PhD, from Liwen Bianji, Edanz Editing China (http://www.liwenbianji.cn/ac), for editing the English text of a draft of this manuscript.

\section{References}

[1] G. X. Qin, J. H. Kang, and A. S. Tang, "Experimental study on abnormal concrete of RCC dam," People's Yangtze River, vol. 39, no. 9, pp. 92-94, 2008.

[2] H. C. Zhang, B. Yang, and X. F. Wang, "Study on temperature control and anti-cracking of xiangbiling RCC arch dam and its application effect," Hydroelectric Power, vol. 44, no. 7, 2018.

[3] Z. Q. Zhang, "Design and stress analysis of RCC arch dam," Journal of Hydraulic Engineering, no. 7, pp. 77-81, 1992.

[4] G. S. Sarkaria and F. R. Andriolo, "Special factors in design of high RCC gravity dams part II," International Design and Construction, no. 8, pp. 17-24, 1995.

[5] Y. L. Lian, "Current status and development of RCC construction technology for water conservancy projects," Water Saving Irrigation, no. 6, p. 82, 2012.

[6] H. W. Reinhardt and S. Xu, "Crack extension resistance based on the cohesive force in concrete," Engineering Fracture Mechanics, vol. 64, no. 5, pp. 563-587, 1999.

[7] M. C. Li, M. X. Zhang, and Y. Y. Wang, "Numerical analysis of temperature field and temperature stress of RCC gravity dam controlled fracture structure considering induced joint," Journal of Hydraulic Engineering, vol. 48, no. 5, pp. 551-559, 2017.

[8] L. Pei, P. Dai, K. He, Z. Wu, and J. Chen, "Reliability analysis of temperature control of high RCC arch dam," Advances in Science \& Technology of Water Resources, 2016.

[9] A. A. Abdulrazeg, J. Noorzaei, M. S. Jaafar, P. Khanehzaei, and T. A. Mohamed, "Thermal and structural analysis of rcc double-curvature arch dam," Journal of Civil Engineering and Management, vol. 20, no. 3, pp. 434-455, 2014. 
[10] X. H. Liu, Y. Duan, W. Zhou, and X. Chang, "Modeling the piped water cooling of a concrete dam using the heat-fluid coupling method," Journal of Engineering Mechanics, vol. 139, no. 9, pp. 1278-1289, 2013.

[11] A. A. Abdulrazeg, J. Noorzaei, P. Khanehzaei et al., "Effect of temperature and creep on roller compacted concrete dam during the construction stages," Computer Modeling in Engineering and Sciences, vol. 68, no. 3, pp. 239-268, 2010.

[12] A. Gaspar, F. Lopez-Caballero, A. Modaressi-FarahmandRazavi, and A. Gomes-Correia, "Methodology for a probabilistic analysis of an RCC gravity dam construction. Modelling of temperature, hydration degree and ageing degree fields," Engineering Structures, vol. 65, pp. 99-110, 2014.

[13] V. Kuzmanovic, L. Savic, and N. Mladenovic, "Computation of thermal-stresses and contraction joint distance of RCC dams," Journal of Thermal Stresses, vol. 36, no. 2, pp. 112-134, 2013.

[14] S. Jiang, C. Du, and Y. Hong, "Failure analysis of a cracked concrete gravity dam under earthquake," Engineering Failure Analysis, vol. 33, no. 5, pp. 265-280, 2013.

[15] P. Lin, B. Huang, Q. Li, and R. Wang, "Hazard and seismic reinforcement analysis for typical large dams following the Wenchuan earthquake," Engineering Geology, vol. 194, pp. 86-97, 2015.

[16] D. Liu, Z. Li, and J. Liu, "Experimental study on real-time control of roller compacted concrete dam compaction quality using unit compaction energy indices," Construction and Building Materials, vol. 96, pp. 567-575, 2015.

[17] L. Zhang, J. Xu, and X. Chen, "Fracture test of RCC," Journal of Hydraulic Engineering, no. 5, pp. 45-49, 2001.

[18] G. Chen, L. Zhang, and J. K. Chen, "Application of composite form method in reliability analysis of arch dam structure," Journal of Hydraulic Engineering, no. 2, pp. 99-101, 2003.

[19] X. G. Chen, Y. P. Song, and Z. M. Song, "Study on the equivalent strength and fracture of RCC penetrating induced joints," Journal of Hydraulic Engineering, no. 3, pp. 99-102, 2004.

[20] L. Zhang, J. Xu, X. Chen et al., "Experimental study on fracture of roller compacted concrete," Journal of Hydraulic Engineering, no. 5, pp. 45-49, 2001.

[21] H. C. Liu, Z. M. Wu, and Y. P. Song, "A study on the equivalent stress cracking criterion for induction joints of Rcc arch dam," Journal of Civil Engineering, no. 12, pp. 24-31, 2005.

[22] S. Y. Zeng and Q. Ma, "Study on tectonic fracture in high RCC arch dam," Hydroelectric Power, no. 2, pp. 3-5, 1998. 